\title{
The Influence of Latent Viral Infection on Rate of Cognitive Decline over 4 Years
}

\author{
Allison E. Aiello, PhD, ${ }^{*}$ Mary N. Haan, MPH, DrPH,,$^{\dagger}$ Lynn Blythe, BS, ${ }^{\dagger}$ Kari Moore, MS, ${ }^{\dagger}$ \\ Jeffrey M. Gonzalez, MS, ${ }^{\dagger}$ and William Jagust, $\mathrm{MD}^{\ddagger}$
}

OBJECTIVES: To examine whether cytomegalovirus (CMV) and herpes simplex virus type-1 (HSV-1) are associated with cognitive decline over a 4-year period and to assess whether C-reactive protein (CRP) modifies these relationships.

DESIGN: Prospective cohort study over a 4-year period. SETTING: Community-dwelling elderly population.

PARTICIPANTS: The sample was a subset $(1,204 / 1,789)$ of participants in the Sacramento Area Latino Study on Aging (SALSA) aged 60 to 100.

MEASUREMENTS: Participants were screened annually over a 4-year period for cognitive function and episodic memory. Cognitive function was assessed using the modified Mini-Mental State Examination, and episodic memory was assessed using a word list-learning test of delayed recall. Baseline serum samples were assayed for levels of immunoglobulin G antibodies to CMV and HSV-1 and for levels of CRP.

RESULTS: There was a significantly higher rate of cognitive decline over the 4-year period in subjects with the highest CMV antibody levels at baseline than in individuals with the lowest levels $(\beta=-0.053$, standard error $=$ $0.018 ; P=.003)$, after controlling for age, sex, education, income, and chronic health conditions. There was no association between HSV-1 antibody levels and cognitive decline. CRP did not modify the relationship between viral antibody levels and cognitive decline.

From the * Center for Social Epidemiology and Population Health and ${ }^{\dagger}$ Department of Epidemiology, School of Public Health, University of Michigan, Ann Arbor, Michigan; and ${ }^{\ddagger}$ School of Public Health and Helen Wills Neuroscience Institute, University of California at Berkeley, Berkeley, California.

A published abstract of the initial findings, "Novel Infectious Biomarkers of Cognitive Impairment," was presented at the Alzheimer's Association International Prevention of Dementia Conference, June 18-21, 2005, Washington, DC. In addition, we were invited to submit a brief report to the journal Research and Practice in Alzheimer's Disease and Cognitive Decline on the findings presented at the Alzheimer's Association International Prevention of Dementia Conference. This four-page invited brief report is currently under review and has limited overlap with the findings reported in this study.

Address correspondence to Allison E. Aiello, PhD, Assistant Professor of Epidemiology, Center for Social Epidemiology and Population Health, 1214 S. University, 2nd floor, Ann Arbor, MI 48104. E-mail: aielloa@umich.edu

DOI: 10.1111/j.1532-5415.2006.00796.x
CONCLUSION: This is the first study to show that individuals with higher levels of antibody to CMV experience a more-rapid rate of cognitive decline than those with lower levels. Understanding the mechanisms by which CMV influences cognition may aid development of intervention strategies targeting infection, viral reactivation, and immune response over the life course. J Am Geriatr Soc 54:1046-1054, 2006.

Key words: herpes; dementia; rate of cognitive decline; elderly; community

$\mathrm{C}$ ognitive impairment and dementia are important causes of increased morbidity and mortality in older people. As the aging population continues to grow in the United States, the healthcare needs associated with treating and caring for elderly individuals with dementia are projected to pose significant public health and economic burdens. ${ }^{1,2}$ Researchers agree that it is critical to diagnose dementia at an early stage to implement prevention efforts and maximize treatment benefits. ${ }^{3}$ Studies have implicated biological inflammatory markers, such as C-reactive protein (CRP) and cytokines, as predictors of cognitive decline. ${ }^{4-6} \mathrm{Al}$ though the identification of such inflammatory markers has helped unveil the biological pathways that influence dementia risk, limited information is available regarding the pathophysiological mechanisms that modulate changes in the level of these markers.

One potential ubiquitous early-life environmental exposure that may act as a proinflammatory factor is latent infection with herpesviruses, such as cytomegalovirus (CMV) and herpes simplex virus type 1 (HSV-1). CMV and HSV-1 are extremely prevalent in older people, and identification of these viruses in areas of the brain of individuals affected by Alzheimer's disease have led to the hypothesis that herpesviruses are causal agents or promoters of dementia. ${ }^{7}$ The pathways by which herpesviruses may influence dementia are not well understood. It is possible that stress-induced viral reactivation may lead to immunerelated inflammatory cascades and cytokine accumulation, resulting in direct damage to neurons. ${ }^{8}$ It has been suggested that, even when herpesviruses are in a latent state, 
inflammatory processes are ongoing and may be enhanced by age-related changes in the immune system. For example, latent CMV has been shown to be highly immunostimulatory in older people and is associated with increased CMVspecific CD8 + T-cell proliferation, which may result in heightened levels of circulating inflammatory cytokines. ${ }^{9}$

Given the potential pathways between infection, inflammation, and cognitive decline, it was hypothesized that latent viral infections directly influence cognition and that CRP modulates the relationship between herpesviruses and cognitive decline. The specific aims of this study were to examine whether levels of viral antibodies to CMV and HSV-1 influenced cognitive decline over a 4-year follow-up period and to assess whether CRP modifies the effect of viral antibody levels on cognitive decline.

\section{METHODS}

\section{Study Population}

The participants were derived from the Sacramento Area Latino Study on Aging (SALSA). SALSA is a large, ongoing, prospective cohort study of Mexican Americans living in the community who were aged 60 to 100 at baseline in $1998 / 99$. A subsample of participants $(\mathrm{N}=1,204)$ from the overall SALSA cohort $(\mathrm{N}=1,789)$ with available blood samples and who had at least two sequential follow-up visits starting from baseline were included in the analyses. The details of the SALSA study have been discussed previously, and the institutional review board at the University of Michigan approved all analyses. ${ }^{10}$

\section{Study Design}

Baseline data collection for the SALSA began in 1998 with a 2-hour interview at participants' homes. Each year, participants were screened for cognitive functioning using the modified Mini-Mental State Examination (3MSE) and for episodic memory using a word list-learning test of delayed recall (DEL-REC). ${ }^{10}$ Those falling below the educationand age-adjusted 20th percentile on either of these tests were referred for further neuropsychological tests, a clinical examination, and expert adjudication of dementia and cognitive impairment diagnoses. A subsample, including $20 \%$ of subjects with values above the 3MSE or DEL-REC cutpoints, underwent further evaluations aimed at determining the sensitivity of screening tests, as described elsewhere. ${ }^{10}$ Lifestyle, health, and demographic factors were collected annually during the participant interviews. Information on education, socioeconomic status of the household, medical history, and duration and date of diagnoses for 35 health conditions were gathered. Direct clinical evaluations were used to measure blood pressure and weight/height and waist/hip ratios.

\section{Laboratory Analyses}

The laboratory staff was unaware of the diagnostic classification of the test samples. A commercially available enzyme-linked immunosorbent assay (ELISA) immunoglobulin $\mathrm{G}(\mathrm{IgG})$ detection system (Wampole Laboratories, Princeton, NJ) was used to analyze the level (expressed as optical density units) of IgG reactive to HSV-1 and CMV in aliquots of continuously frozen $\left(-70^{\circ} \mathrm{C}\right)$ serum samples.
Following manufacturer instructions, samples were assessed for the level of IgG antibody signal as expressed by the mean optical density value. The sensitivity and specificity of the assay for HSV-1 are reported to be $97.1 \%$ and $96.8 \%$, respectively, and for CMV, the sensitivity and specificity are reported to be $96.4 \%$ and $93.3 \%$, respectively. Each 96-well commercial ELISA kit contained controls and internal calibrations.

CRP was analyzed using the CRP Ultra Wide Range Reagent Kit latex-enhanced immunoassay (Equal Diagnostics, Exton, PA). This is a widely used in vitro diagnostic test for the quantitative determination of CRP in human serum. Manufacturer's instructions were followed, and CRP levels were determined using an automated analyzer and a prepared calibration curve. Using the highly sensitive method, the kit provides a range of measurable CRP from $0.05 \mathrm{mg} / \mathrm{L}$ to $80.0 \mathrm{mg} / \mathrm{L}$. Results greater than $80.0 \mathrm{mg} / \mathrm{L}$ were diluted, retested, and multiplied by the dilution factor.

\section{Statistical Analyses}

For descriptive demographic variables shown in Tables 1 and 2, $t$ tests were used to compare means, and chi-square or Fisher exact tests to compare proportions. Mixed models were used to estimate the effect of viral antibody levels measured at baseline on changes in cognitive functioning over a 4-year period. ${ }^{11}$ The measures of cognitive functioning were the 3MSE and DEL-REC scores at baseline and each of a maximum of four follow-up measurements. Because the distribution of 3MSE scores was negatively skewed, a natural logarithmic transformation was applied to this outcome to meet the model assumption of normality. ${ }^{12}$ All models presented with 3MSE as the outcome used the transformed version of this measure. In addition, measured CRP levels in $\mathrm{mg} / \mathrm{L}$ were skewed and were therefore $\log$ transformed (lnCRP) to maintain a normal distribution.

In the initial mixed-model analysis, the independent influence of several potential covariates that have been identified as risk factors for dementia was explored. ${ }^{13}$ These covariates were age, sex, education, income, number of health conditions reported at baseline (diabetes mellitus, hypertension, myocardial infarction, angina pectoris, heart failure, atrial fibrillation, rheumatic fever/heart valve problem, cancer, and stroke), smoking, body mass index, CRP levels, Center for Epidemiologic Studies Depression Scale scores, ${ }^{14}$ and hetero- or homozygosity for apolipoprotein E4 genotype (ApoE-4). Each covariate was assessed in repeated-measures mixed models representing decline in 3MSE. In addition, the relationship between each of these potential covariates and the main predictor variables (i.e., baseline CMV and HSV-1 antibody levels) were examined using linear regression analyses. Consistent with cutoffs commonly used in the epidemiological literature, only covariates that were significantly associated with baseline cognitive scores at $\alpha=0.05$ level and with cognitive decline (i.e., covariate by time) at $\alpha=0.10$ level were included. The covariates that exhibited statistical significance using these criteria were age, sex, education, income, and number of health conditions at baseline.

Modifications were made to the mixed-model covariance structure to obtain better fitting models, as indicated by a lower Akaike Information Criterion. Based on the 
Table 1. Descriptive Statistics for the Sacramento Area Latino Study on Aging Cohort Analysis Sample $(N=1,204)$

\begin{tabular}{|c|c|}
\hline Characteristic & Value \\
\hline Age at baseline, mean $\pm \mathrm{SD}^{*}$ & $70.3 \pm 6.8$ \\
\hline Female, \% & 58 \\
\hline Place of birth Mexico or other & 46.3 \\
\hline Latin American country, $\%^{\dagger}$ & \\
\hline $\begin{array}{l}\text { Number of baseline health } \\
\text { conditions, mean } \pm S D\end{array}$ & $1.3 \pm 1.1$ \\
\hline Apolipoprotein-E4 positive ${ }^{\ddagger}, \%$ & 5.7 \\
\hline \multicolumn{2}{|l|}{ Education, years, \%§ } \\
\hline $0-3$ & 28.7 \\
\hline $4-11$ & 37.9 \\
\hline$\geq 12$ & 33.4 \\
\hline \multicolumn{2}{|l|}{ Income per month, $\$, \% \S$} \\
\hline$<1,000$ & 40.5 \\
\hline $1,000-1,999$ & 31.9 \\
\hline$\geq 2,000$ & 27.6 \\
\hline \multicolumn{2}{|c|}{$3 \mathrm{MSE}$ score, mean $\pm \mathrm{SD}$ (median) $\|$} \\
\hline Baseline & $85.7 \pm 13.0(89)$ \\
\hline Follow-up year 1 & $85.4 \pm 15.2(90)$ \\
\hline Follow-up year 2 & $89.6 \pm 11.4(93)$ \\
\hline Follow-up year 3 & $88.9 \pm 12.5(93)$ \\
\hline Follow-up year 4 & $87.1 \pm 15.5(92)$ \\
\hline \multicolumn{2}{|l|}{ DEL-REC score, mean \pm SD } \\
\hline Baseline & $8.6 \pm 3.1$ \\
\hline Follow-up year 1 & $8.0 \pm 3.3$ \\
\hline Follow-up year 2 & $8.8 \pm 2.6$ \\
\hline Follow-up year 3 & $7.9 \pm 2.8$ \\
\hline Follow-up year 4 & $8.7 \pm 3.1$ \\
\hline
\end{tabular}

* The mean age of the analysis sample was significantly younger than of those excluded (76.4 vs $77.3, P=.01)$.

${ }^{\dagger}$ A smaller percentage of individuals in the analysis sample were born in Mexico than of those excluded $(46.3 \%$ vs $60.7 \%, P<.001)$.

${ }^{\ddagger}$ Information on apolipoprotein-E4 status was not available for 80 individuals.

$\S^{\S}$ Education and income levels of the analysis sample were significantly higher than of those excluded (all $P<.001$ ).

"For Modified Mini-Mental State Examination (3MSE) scores, the mean and median are presented, because these values were not normally distributed. Individuals in the analyses sample had significantly higher 3MSE scores at baseline $(P<.001)$ and at Year $3(P=.04)$ than those excluded.

"Delayed Recall Word List (DEL-REC), scores were significantly higher in the analysis sample at baseline $(P<.001)$ and Year $4(P=.04)$ than for those excluded.

$\mathrm{SD}=$ standard deviation

modifications, all models presented assumed a first-order auto-regressive covariance structure for the within-subject error and contained a random intercept allowing variation in baseline measures of cognition. Also, to account for the curvilinear pattern of change in cognitive functioning over time as measured using the $3 \mathrm{MSE}$, all models for this outcome contained a quadratic term representing the year (time) of cognitive test scores. Mixed models are presented in two forms: (1) treating CMV and HSV-1 antibody values as continuous variables, which assumes a linear relationship between viral IgG antibody levels and decline in cognition over time, and (2) a transformation of CMV and HSV-1 antibody values into quartiles, where the first quartile is considered the referent group for comparison with the second, third, and fourth quartiles of viral antibody levels. This form of the model allows an assessment of potential non-
Table 2. Proportion Seropositive for Cytomegalovirus (CMV) and Herpes Simplex Virus Type-1 (HSV-1) and Levels of C-Reactive Protein (CRP)

\begin{tabular}{|c|c|c|c|}
\hline Biomarker & $\begin{array}{l}\text { Women } \\
(n=698)\end{array}$ & $\begin{array}{c}\text { Men } \\
(n=506)\end{array}$ & $\begin{array}{c}\text { Total Sample } \\
(\mathrm{N}=1,204)\end{array}$ \\
\hline \multicolumn{4}{|c|}{ Virus immunoglobulin G antibody levels* } \\
\hline CMV & 97.56 & 95.26 & 96.59 \\
\hline HSV & 98.57 & 97.63 & 98.17 \\
\hline \multicolumn{4}{|c|}{ CRP levels $(\mathrm{mg} / \mathrm{L})^{\dagger}$} \\
\hline Low $(<1)$ & 12.63 & 25.69 & 18.12 \\
\hline Medium (1-3) & 26.40 & 33.20 & 29.26 \\
\hline High $(>3)$ & 60.98 & 41.11 & 52.62 \\
\hline
\end{tabular}

* Based on enzyme-linked immunosorbent assay clinical cutpoints for seropositivity.

${ }^{\dagger}$ Cutpoints based on Centers for Disease Control and Prevention and the American Heart Association. ${ }^{16}$

linear relationships and provides a means of assessing a dose-response effect of viral antibody levels on rate of cognitive decline. Details on the application of mixed models to cognitive decline have been described previously. ${ }^{15}$

The unadjusted mixed models for assessing the relationship between viral antibody level and cognitive decline included a term for the viral antibody value, time (since baseline), and the interaction of the viral antibody value with year. The next model (initial model) contained the same variables as the unadjusted model with the addition of age and sex and their interaction with time. The final models contained all of the variables in the initial model along with all other significant covariates (education, income, and number of baseline health conditions).

To examine whether lnCRP modified the effect of viral antibody levels on global cognitive decline (3MSE), unadjusted and adjusted mixed models with three-way interaction terms were fitted. For example, the unadjusted effect modification model for CMV and InCRP included the following terms: CMV (antibody levels as a continuous value), CRP, time, CMV by time, lnCRP by time, lnCRP by CMV, and CMV by CRP by time. Analyses were conducted using SAS Version 9.1 (SAS Institute, Inc., Cary, NC) with the corresponding commands for the MIXED model procedure.

\section{RESULTS}

\section{Demographic Characteristics}

The demographic characteristics of subjects who were included in the analyses $(\mathrm{N}=1,204)$ are shown in Table 1 . Using the clinical cutpoint designated by the ELISA test kits, $97 \%$ of the study subjects showed signs of prior infection with CMV, and $98 \%$ showed signs of prior infection with HSV-1 (Table 2). Levels of CMV IgG antibodies were significantly higher in women than men (both $P<.001$ ), but there was no significant difference in levels of HSV-1 (Figure 1). Most of the participants had CRP levels that have been considered to indicate high risk for cardiovascular conditions; CRP levels varied by sex. ${ }^{16}$ There were significant, but modest, linear associations between antibody levels of HSV-1 and CMV $(\beta=0.147, P<.001)$, and CMV 


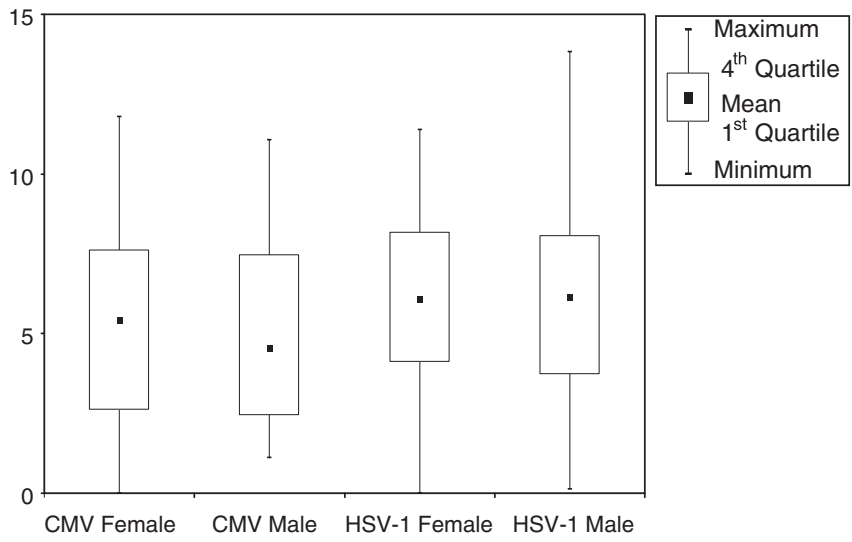

Figure 1. Quartile distribution of cytomegalovirus (CMV) and herpes simplex virus type 1 (HSV-1) immunoglobulin G (Ig6) antibody values. The box-plots show the IgG antibody optical density units as measured using enzyme-linked immunosorbent assay.

and $\operatorname{lnCRP}(\beta=0.113, P<.023)$, controlling for age, sex, and number of health conditions. There was no significant linear association between $\operatorname{lnCRP}$ and HSV-1 antibody levels $(\beta=0.050, P>.26)$.

\section{Viral Antibody Levels and Rate of Cognitive Decline}

A one-unit increase in CMV IgG antibody level was associated with a significant decline in 3MSE score over the 4year period $(\beta=-0.274$, standard error $=0.023$; $P<.001)$ controlling for age, sex, education, income, and chronic health conditions. This same trend was observed for the quartile analyses. Tables 3 and 4 show the initial and final mixed-model effect estimates for quartiles of viral antibody levels on annual rate of cognitive decline as measured using the 3MSE at each of the five yearly assessments (i.e., baseline, Year 1, Year 2, Year 3, Year 4). As denoted by the significant follow-up-time parameter estimates in $\mathrm{Ta}$ bles 3 and 4, subjects showed an increase in 3MSE scores over the 4-year study period, indicating a moderate 3MSE practice effect over time.

Individuals with CMV antibody levels in the upper quartiles (4th and $3 \mathrm{rd}$ ) had a more rapid rate of cognitive decline over the 4-year period than individuals in the lowest category of CMV antibody levels (1st quartile), controlling for all covariates (age, sex, education, income, and health conditions). There was an increase in the magnitude of the difference, with each quartile compared with the referent group.

In contrast to CMV, the HSV-1 antibody levels did not significantly influence rate of cognitive decline over the 4year period (Table 4). In addition, neither CMV nor HSV-1 antibody levels were significantly associated with baseline DEL-REC scores in final models (data not shown, all $P>.05)$ or declines in the DEL-REC over the 4-year period (data not shown, all $P>.10$ ).

\section{Effect Modification by CRP on Cognitive Decline}

There was no significant interaction between increased viral antibody levels and $\operatorname{lnCRP}$ on rate of cognitive decline (i.e., CMV by lnCRP by time), controlling for age, sex, health conditions, education, and income (Table 5). In the final effect-modification model for CMV, the relationship between higher CMV antibody levels and rate of cognitive decline (CMV by time) remained significant, regardless of the inclusion of variables representing $\operatorname{lnCRP}$, its interaction with time, the lnCRP-by-CMV interaction, the three-way interaction term (lnCRP by CMV by time), and covariates. Effect modification with DEL-REC scores as an outcome was not assessed, because neither CMV nor HSV-1 was independently associated with decline in these test scores in final models.

\section{DISCUSSION}

This was the first study to examine the relationship between herpesvirus antibody levels and rate of cognitive decline over a 4-year period in community-dwelling elderly individuals in the United States. The strengths of this novel

Table 3. Relationship Between Cytomegalovirus (CMV) Antibody Level and Cognitive Decline

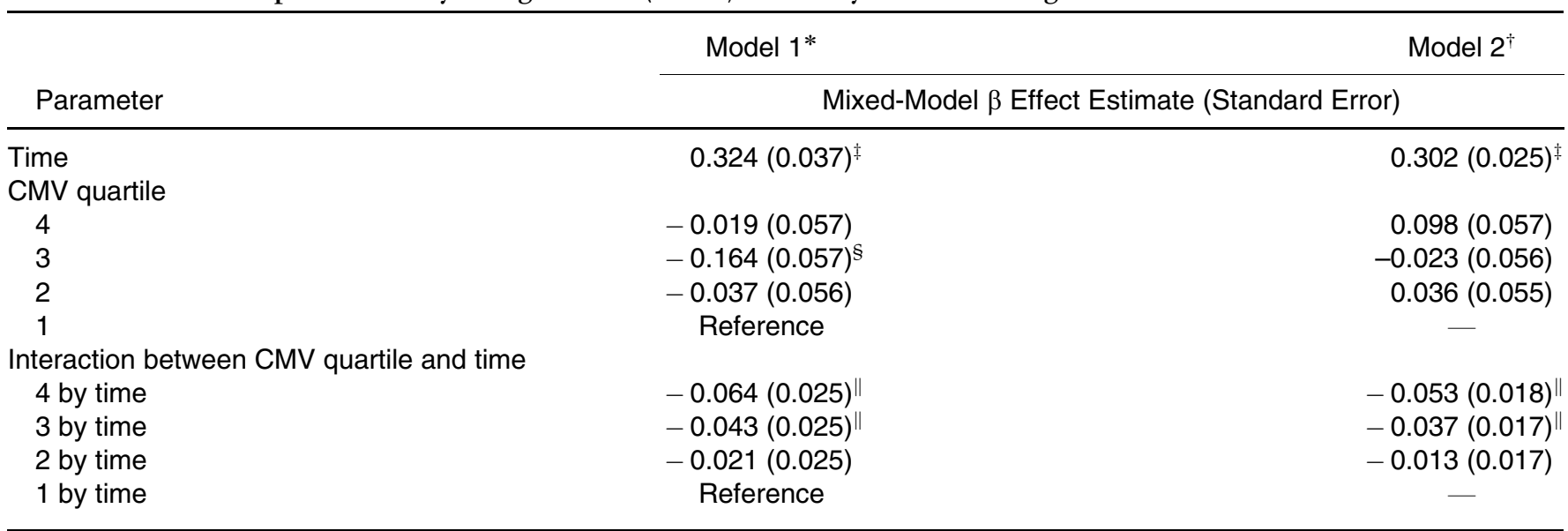

Note: Results compare the effect of each quartile of CMV immunoglobulin G antibody level with the lowest quartile (1) on Modified Mini-Mental State Examination scores over the 4-year period.

* Adjusted for age, sex, and their interaction with time.

${ }^{\dagger}$ Adjusted for age, sex, their interaction with time, education, income, and number of baseline health conditions.

$P<{ }^{\ddagger} .001 ;{ }^{\S} .05$; and ${ }^{\|} .10$ for interaction terms. 
Table 4. Relationship Between Herpes Simplex Virus Type 1 (HSV-1) Antibody Level and Cognitive Decline

\begin{tabular}{|c|c|c|}
\hline Parameter & Model $1^{*}$ & Model $2^{\dagger}$ \\
\hline Time & $0.299(0.038)^{\ddagger}$ & $0.278(0.026)^{\ddagger}$ \\
\hline \multicolumn{3}{|l|}{ HSV-1 quartile } \\
\hline 4 & $-0.111(0.056)$ & $0.026(0.056)$ \\
\hline 3 & $-0.078(0.056)$ & $0.013(0.056)$ \\
\hline \multicolumn{3}{|c|}{ Interaction between HSV-1 quartile and time } \\
\hline 4 by time & $-0.018(0.025)$ & $0.003(0.017)$ \\
\hline 3 by time & $0.013(0.025)$ & $0.011(0.018)$ \\
\hline 2 by time & $0.021(0.025)$ & $0.010(0.017)$ \\
\hline 1 by time & Reference & - \\
\hline
\end{tabular}

Note: Results compare the effect of each quartile of HSV-1 immunoglobulin G antibody level with the lowest quartile (1) on Modified Mini-Mental State Examination scores over the 4-year period.

* Adjusted for age, sex, and their interaction with time.

${ }^{\dagger}$ Adjusted for age, sex, their interaction with time, education, income, and number of baseline health conditions.

${ }^{\ddagger}$ Significant at $P<.001$.

study include the rigorous, widely accepted, standardized methods for ascertaining cognitive functioning; assessment and control of numerous potential covariates; and use of a prospective study design and population-based cohort. In addition, mixed-model analyses were used to assess potential dose-response relationships and to model corresponding trajectories of cognitive decline over a 4-year period. The results suggest that high CMV IgG antibody levels are an important marker of cognitive decline in older people, even after controlling for major risk factors such as age, education, sex, and chronic health conditions. A dose-response relationship was observed in which each increase in quartile of CMV antibody level resulted in a more rapid rate of cognitive decline. The general inflammatory marker CRP in the study population did not modify this relationship.

\section{CMV and Cognitive Decline}

The findings of an association between high CMV IgG antibody levels and cognitive decline are consistent with one previous epidemiological study that identified a relationship between herpesvirus coinfection and cognitive impairment in elderly Finnish patients with underlying vascular disease. ${ }^{17}$ The study showed that Finnish subjects who tested positive for serum antibodies to CMV, HSV-1, and HSV-2 at baseline had twice the risk of decline in cognitive functioning scores after 1 year as those who did not test positive. ${ }^{17}$ Exposure status was measured according to the presence or absence of IgG antibodies to each virus and combined seropositivity. The use of seropositivity (i.e., positive or negative for CMV or HSV IgG antibodies or both) as a predictor can result in small comparison groups of nonexposed individuals, given the high prevalence of prior infection with HSV-1 and CMV in the general population. ${ }^{18-}$ 20 The use of seropositivity status as an exposure variable has been shown to result in instability of regression estimates due to random variability from small cell sizes and residual confounding. ${ }^{18}$ In contrast to the previous study, ${ }^{17}$ the current study used antibody levels as continuous and quartile-transformed exposure measures to assess linear and potential dose-response relationships, as well as to overcome analytical limitations associated with extremely prevalent predictor variables. The findings regarding CMV

Table 5. Effect Modification by $\log _{10}$ C-Reactive Protein $(\operatorname{lnCRP})$ on Cognitive Decline (3MSE Score)

\begin{tabular}{lcr}
\hline & Model $1^{*}$ & Model $2^{\dagger}$ \\
\cline { 2 - 3 } Parameter (Quartile) & Mixed-Model $\beta$ Effect Estimate (Standard Error) \\
\hline Effect modification of CMV by InCRP on cognitive decline & & $-0.010(0.003)^{\ddagger}$ \\
CMV by time & $-0.014(0.003)^{\ddagger}$ & $0.001(0.003)$ \\
CMV by InCRP by time & $0.001(0.003)$ & $-0.002(0.004)$ \\
Effect modification of HSV-1 by InCRP on cognitive decline & & $0.001(0.003)$ \\
HSV-1 by time & $-0.003(0.004)$ & $-0.001(0.003)$ \\
HSV-1 by InCRP by time & \\
&
\end{tabular}


antibody levels and cognitive decline were robust even after controlling for several significant covariates that have been identified as risk factors for cognitive decline, including age, education, and numerous health conditions.

It has been shown that acute symptomatic infection in elderly hospitalized individuals, such as urinary tract infection, can trigger transient changes in cognition and attention, resulting in episodes of delirium. ${ }^{21}$ These bouts of delirium are a major risk factor for subsequent functional decline and dementia diagnoses. ${ }^{22,23}$ In contrast to acute systemic infection, CMV is a lifelong latent infection that generally does not cause clinical symptoms in healthy individuals. ${ }^{19}$ It is possible that latent CMV plays a role in cognitive decline via immune system modulation and associated inflammatory cytokine cascades rather than direct pathological effects attributed to active infection. Novel research findings have shown that latent CMV infection in older people is an important component of a set of immunological parameters designated the "immunological risk phenotype." ${ }^{24}$ This set of immunological markers, including latent $\mathrm{CMV}$ infection, high cluster of differentiation (CD) 8 cells, low CD4 cell percentages, and poor T-cell proliferation, is predictive of mortality in healthy elderly individuals. ${ }^{25}$

Latent CMV is present in CD34+ bone marrow precursor cells and during differentiation of these precursors, $\mathrm{CMV}$ may chronically stimulate the immune system. ${ }^{26} \mathrm{Sev}$ eral studies have now reported that there is large clonal expansion of CMV-specific CD8+ T-cells in older people and that the expansion of these clones are not a consequence of deteriorating health, comorbidity, or a general loss of immune control over the virus. ${ }^{9,25,27-30}$ The expansion of CMV-specific clones reduces the availability of CD8+ T-cell carrying receptors that are specific for pathogens or foreign antigens other than CMV, thereby limiting the capacity of the immune system to mount an efficient response. ${ }^{31}$ For example, one study reported that a reduced immune response to influenza vaccination was observed in elderly individuals who tested seropositive for latent CMV. ${ }^{31}$ Moreover, they showed that high levels of CMV IgG antibody are strongly correlated with increases in serum cytokines tumor necrosis factor (TNF)- $\alpha$ and interleukin (IL)-6 in older people. ${ }^{31}$ CMV-specific CD8+ T-cells also have the ability to produce interferon (FN)- $\gamma \cdot{ }^{9}$ Thus, an accumulation of CMV-specific CD8+ T-cells may lead to an increase in several circulating inflammatory cytokines, including TNF- $\alpha$, IFN- $\gamma$, and IL-6. This increased chronic peripheral cytokine concentration and reduced repertoire of T-cells with specificity for pathogens other than CMV is likely to influence pathophysiological changes associated with cognitive impairment and dementia. ${ }^{32}$

The finding of a dose-response relationship between CMV IgG antibody levels and cognitive decline is further evidence for an infection-related immunological pathway. Research is needed to assess whether cytokines, such as IL-6 and TNF- $\alpha$, modify the relationship between CMV and cognitive decline, because these markers may increase with heightened levels of CD4+ CMV-specific T-cells associated with the aging process. $^{9}$ Recently, a cross-sectional study showed a significant association between CMV infection and frailty that was strongly modified by increased IL-6 levels. ${ }^{33}$ Their findings suggest that proinflammatory cyto- kines may be an important modulator of latent CMV infection in older people in relation to declines in physical functioning. ${ }^{33}$

\section{HSV-1 and Cognitive Decline}

Although a few autopsy-based case-control studies have reported that HSV-1 deoxyribonucleic acid (DNA) is found in a higher proportion of the brains of people with $\mathrm{Alz}$ heimer's disease than in age-matched controls, ${ }^{34-36}$ the majority of these autopsy studies report no association between the presence of the viral DNA and dementia. ${ }^{37-43}$ The results of the current study do not support a relationship between HSV-1 and cognitive decline.

Studies have implicated ApoE-4 as a potential susceptibility genotype for infection with various pathogens, including HSV-1, human immunodeficiency virus, and malaria. ${ }^{44}$ Several case-control studies have indicated that individuals who are positive for the ApoE-4 allele and for HSV-1 DNA in the brain have a greater risk of Alzheimer's disease than those who are ApoE4 positive but do not have virus present in the brain or than those without either the virus or the ApoE-4 allele. ${ }^{38-41}$ This suggests a potential interaction between HSV-1 and ApoE-4 and dementia risk. ${ }^{7}$ It was not possible to identify any studies that have examined interaction between CMV and ApoE-4 and dementia risk. As a consequence of the limited sample size of individuals positive for ApoE-4 (5.7\%), there was insufficient power to explore interactions between E-4 and the viral antibody markers in this study population. Further research is needed to assess potential gene-virus interactions with cognitive decline in large population-based prospective studies.

\section{Effect Modification of Viral Cognitive Trajectories According to CRP}

Two studies have reported a relationship between high CRP levels and cognitive decline. ${ }^{4,5}$ In addition, several researchers have reported an association between high CRP and risk of dementia. ${ }^{45-47}$ The specific mechanisms by which CRP influences cognitive impairment are still unclear. In an in vitro study, CRP has been shown to cause toxicity to neuronal cells, ${ }^{48}$ and studies have identified circulating CRP in the brains of people with Alzheimer's disease. ${ }^{49,50}$ Although CRP has been shown to be a more-sensitive marker of bacterial than viral infection, it also fluctuates with the clinical course of several viral infections, including CMV. ${ }^{51,52} \mathrm{Nev}$ ertheless, there was no indication of an interaction between CRP and viral antibody levels on changes in cognitive scores over the 4-year period in the study population. The association between high CMV antibody levels and rate of decline in 3MSE scores was robust, regardless of the inclusion of CRP levels in the interaction models. This suggests that the effect of high CMV antibody levels on rate of cognitive decline is independent of general inflammatory processes associated with increased CRP. Further study on the pathophysiological pathways by which CMV influences cognitive decline is warranted.

\section{Limitations}

There are potential limitations associated with use of viral antibodies as a marker. For example, high levels of herpes- 
virus IgG antibodies may indicate recent primary infection, but this is unlikely in the study population, because infection with HSV-1 and CMV commonly occurs at young ages. (Eighty percent to $90 \%$ of elderly populations are infected.) ${ }^{19,20}$ There are few data assessing CMV infection in population-based studies of older Mexican Americans. The studies that are available have been conducted in Mexican Americans in other age ranges. ${ }^{53,54}$ These studies generally report a higher prevalence of CMV infection in Mexican Americans than in non-Hispanic whites. The prevalence of prior infection with HSV-1, which is a virus that is similar to $\mathrm{CMV}$ in terms of transmission, exposure, and latency properties, has been shown to be significantly higher in U.S. Hispanics aged 60 and older than in non-Hispanic whites participating in the National Health and Nutrition Examination Survey III. ${ }^{20}$ The seropositivity estimates for HSV-1 observed in the current study are consistent with these nationally representative prevalence estimates of HSV-1 in Hispanic individuals aged 60 and older.

Given that the prevalence of $\mathrm{CMV}$ infection is found to be higher in Mexican Americans, it is also possible that reactivation and reinfection may be more common over the life-course. Such a pattern of infection and reactivation could lead to an increase in circulating levels of inflammatory cytokines as an adult. CMV has been shown to induce IL- 6 and TNF- $\alpha$ from macrophages and microglial cells. ${ }^{55}$ Information was not available on levels of inflammatory cytokines to assess potential correlations with high CMV antibody levels. Further studies of proinflammatory cytokines as modulators of latent CMV infection in older people in relation to cognitive decline are warranted.

There are some data indicating that Latino individuals experience a higher burden of Alzheimer's disease and an earlier onset of symptoms, ${ }^{56-58}$ although it has been difficult to make conclusions regarding these findings because of differences in ethnic composition of Latino groups and because of the potential for ascertainment and selection biases in racial/ethnic comparative studies. ${ }^{59,60}$ Further research is needed to assess whether latent infection and increased burden of inflammatory cytokines may explain the observed higher rates of cognitive decline in Latinos than in non-Latino whites, while taking into consideration variability in ethnic composition within study groups.

Prior HSV-1 and CMV infection are patterned by education and income. ${ }^{19,20}$ There was a significant association between education and income and high CMV and HSV-1 antibody levels in the SALSA participants. Age and education were also significant predictors of cognitive decline. Therefore, age and education and their interaction with time were controlled for in all final models of cognitive decline. The education and income distribution of the SALSA participants was relatively homogenous, with most individuals reporting 4 to 11 years of education and an income of less than $\$ 1,000$ per month.

Several factors have been identified as initiators of reactivation of latent herpesviruses, including age, chronic health conditions, depression/psychosocial stress, and exposure to ultraviolet light. ${ }^{61-66}$ Of these factors, age, chronic conditions, and depression/psychosocial stress have been linked to cognitive decline in older people. ${ }^{67,68}$ Correspondingly, the statistical analyses identified age and chronic health conditions as factors that were associated with higher CMV antibody levels and were also predictive of cognitive decline. Therefore, these variables were controlled for in all of the final models. There is also evidence that depression/psychosocial stress may influence risk of dementia through complex sociobiological pathways. ${ }^{68-70}$ Various markers of psychosocial stress have been correlated with downregulation of specific markers of cellular immune functioning, including reactivation of latent CMV infection. ${ }^{71-73}$ The assessment of depressive symptoms as a measure of psychosocial stress in the SALSA participants was not significantly associated with high CMV IgG antibody levels. In addition, depressive symptoms were not associated with a statistically significant rate of cognitive decline. These findings are consistent with other studies. ${ }^{74,75}$ It has been suggested that depression may be crosssectionally associated with cognitive impairment but does not significantly predict rate of cognitive decline. ${ }^{74,75}$ It is possible that psychosocial stress measures other than depressive symptoms may be related to CMV reactivation and cognitive decline. Further studies are required to examine whether other measure of psychosocial stress, such as discrimination and absence of social support, influence the relationship between CMV antibody levels and cognitive decline.

A few factors may have reduced the ability to detect a significant association between HSV-1 antibody levels and cognitive decline and may have also resulted in an underestimation of the relationship between CMV and rate of cognitive decline. For example, the study population showed a moderate practice effect over the 4-year period, which led to an annual increase in 3MSE scores. Regardless of the presence of this practice effect, participants with high CMV antibody levels showed a significantly faster rate of cognitive decline. In addition, the analyses were limited to subjects who had participated in the study for at least 2 years starting from baseline. This resulted in the exclusion of study participants with higher risk profiles for cognitive decline, including older age and lower levels of education and income. Therefore, the analysis subsample most likely represents participants with generally healthier risk profiles and may have resulted in underestimation of the relationship between the viral antibody measures and cognitive decline.

It was not possible to examine the relationship between infection and specific forms of cognitive decline. For example, earlier research has shown that CMV DNA is found in a higher proportion of the brains of people with vascular dementia than in age-matched controls, ${ }^{35}$ and several studies have implicated CMV infection as a risk factor for cardiovascular disease outcomes. ${ }^{76}$ Research aimed at assessing whether CMV antibody titers are specifically related to risk of cognitive decline associated with vascular dementia is needed.

\section{CONCLUSION}

In summary, this is the first study to suggest that high levels of antibody to CMV are associated with a more-rapid decline in global cognition in a population-based sample of elderly individuals in the United States. Because multiple social and pathophysiological changes most likely influence cognitive decline, an assessment of several markers and 
varying patterns of these markers, including infection, cellular immune response, inflammatory processes, endocrine levels, and genetic and social factors will provide the most insight into mechanisms of cognitive decline in elderly populations. The findings reinforce the need for additional large-scale prospective investigations to determine the influence of CMV antibody levels on rate of development of cognitive impairment or dementia, as well as a broader understanding of the potential mechanisms by which these viral immune measures may affect cognition. Confirmation of these findings will enhance understanding of whether $\mathrm{CMV}$ infection is a causative factor and may affect interventions aimed at targeting infection or viral reactivation over the life-course.

\section{ACKNOWLEDGMENTS}

Financial Disclosure: Funding for the SALSA parent study was aided by a grant from the National Institute of Aging, National Institutes of Health (AG12975). This work used the Chemistry Core of the Michigan Diabetes Research and Training Center, funded by NIH5P60, DK20572, and DK60753 from the National Institute of Diabetes and Digestive and Kidney Diseases. We also acknowledge the Robert Wood Johnson Health and Society Scholar grant at the University of Michigan for funding the viral testing.

Author Contributions: A. E. Aiello conceived the aims of the study, conducted the statistical analyses, and wrote the manuscript. M. N. Haan created the SALSA study and contributed to the design, concepts, and writing of the manuscript. W. Jagust contributed to the concepts and writing of the manuscript. J. Gonzalez assisted with model building and statistical analyses of the data. K. Moore aided in organizing the data and biostatistical analyses. L. Blythe coordinated the laboratory testing and organization of the data.

Sponsor's Role: The only role that the sponsors had was financial support.

\section{REFERENCES}

1. Ernst RL, Hay JW. The U.S. economic and social costs of Alzheimer's disease revisited. Am J Public Health 1994;84:1261-1264.

2. Connell CM, Janevic MR, Gallant MP. The costs of caring: Impact of dementia on family caregivers. J Geriatr Psychiatry Neurol 2001;14:179-187.

3. Chang CY, Silverman DH. Accuracy of early diagnosis and its impact on the management and course of Alzheimer's disease. Expert Rev Mol Diagn 2004;4:63-69.

4. Tilvis RS, Kahonen-Vare MH, Jolkkonen J et al. Predictors of cognitive decline and mortality of aged people over a 10-year period. J Gerontol A Biol Sci Med Sci 2004;59A:M268-M274.

5. Yaffe K, Lindquist K, Penninx BW et al. Inflammatory markers and cognition in well-functioning African-American and white elders. Neurology 2003;61:76-80.

6. Weaver JD, Huang MH, Albert $M$ et al. Interleukin-6 and risk of cognitive decline: MacArthur studies of successful aging. Neurology 2002;59:371-378.

7. Itzhaki RF, Wozniak MA, Appelt DM et al. Infiltration of the brain by pathogens causes Alzheimer's disease. Neurobiol Aging 2004;25:619-627.

8. Ringheim GE, Conant K. Neurodegenerative disease and the neuroimmune axis (Alzheimer's and Parkinson's disease, and viral infections). J Neuroimmunol 2004;147:43-49.

9. Almanzar G, Schwaiger S, Jenewein B et al. Long-term cytomegalovirus infection leads to significant changes in the composition of the CD8 + T-cell repertoire, which may be the basis for an imbalance in the cytokine production profile in elderly persons. J Virol 2005;79:3675-3683.

10. Haan MN, Mungas DM, Gonzalez HM et al. Prevalence of dementia in older latinos: The influence of type 2 diabetes mellitus, stroke and genetic factors. J Am Geriatr Soc 2003;51:169-177.
11. Verbeke G, Molenberghs G. Linear Mixed Models for Longitudinal Data. New York: Springer-Verlag, 2000.

12. Osborne J. Notes on the use of data transformations. Pract Assess Res Eval 2002;8:1-7.

13. Ritchie K, Lovestone S. The dementias. Lancet 2002;360:1759-1766.

14. Kohout FJ, Berkman LF, Evans DA et al. Two shorter forms of the CES-D (Center for Epidemiological Studies Depression) depression symptoms index. J Aging Health 1993;5:179-193.

15. Wilson RS, Beckett LA, Barnes LL et al. Individual differences in rates of change in cognitive abilities of older persons. Psychol Aging 2002;17:179_ 193.

16. Glaser R, Pearson GR, Jones JF et al. Stress-related activation of Epstein-Barr virus. Brain Behav Immun 1991;5:219-232.

17. Strandberg TE, Pitkala KH, Linnavuori KH et al. Impact of viral and bacterial burden on cognitive impairment in elderly persons with cardiovascular diseases. Stroke 2003;34:2126-2131.

18. Rothenbacher D, Brenner H, Hoffmeister A et al. Relationship between infectious burden, systemic inflammatory response, and risk of stable coronary artery disease: Role of confounding and reference group. Atherosclerosis 2003;170:339-345.

19. de Jong MD, Galasso GJ, Gazzard B et al. Summary of the II International Symposium on Cytomegalovirus. Antiviral Res 1998;39:141-162.

20. Xu F, Schillinger JA, Sternberg MR et al. Seroprevalence and coinfection with herpes simplex virus type 1 and type 2 in the United States, 1988-1994. J Infect Dis 2002;185:1019-1024.

21. Schor JD, Levkoff SE, Lipsitz LA et al. Risk factors for delirium in hospitalized elderly. JAMA 1992;267:827-831.

22. Murray AM, Levkoff SE, Wetle TT et al. Acute delirium and functional decline in the hospitalized elderly patient. J Gerontol 1993;48:M181-M186.

23. Rockwood K, Cosway S, Carver D et al. The risk of dementia and death after delirium. Age Ageing 1999;28:551-556.

24. Pawelec G, Akbar A, Caruso C et al. Is immunosenescence infectious? Trends Immunol 2004;25:406-410.

25. Nilsson BO, Ernerudh J, Johansson B et al. Morbidity does not influence the Tcell immune risk phenotype in the elderly: Findings in the Swedish NONA Immune Study using sample selection protocols. Mech Ageing Dev 2003;124:469-476.

26. Looney RJ, Falsey A, Campbell D et al. Role of cytomegalovirus in the T cell changes seen in elderly individuals. Clin Immunol 1999;90:213-219.

27. Wikby A, Ferguson F, Forsey R et al. An immune risk phenotype, cognitive impairment, and survival in very late life: Impact of allostatic load in Swedish octogenarian and nonagenarian humans. J Gerontol A Biol Sci Med Sci 2005;60A:M556-M565.

28. Ouyang Q, Wagner WM, Zheng W et al. Dysfunctional CMV-specific CD8 (+) T cells accumulate in the elderly. Exp Gerontol 2004;39:607-613.

29. Ouyang Q, Wagner WM, Wikby A et al. Large numbers of dysfunctional CD8 + T lymphocytes bearing receptors for a single dominant CMV epitope in the very old. J Clin Immunol 2003;23:247-257.

30. Khan N, Shariff N, Cobbold M et al. Cytomegalovirus seropositivity drives the CD8 T cell repertoire toward greater clonality in healthy elderly individuals. J Immunol 2002;169:1984-1992.

31. Trzonkowski P, Mysliwska J, Szmit E et al. Association between cytomegalovirus infection, enhanced proinflammatory response and low level of antihemagglutinins during the anti-influenza vaccination - an impact of immunosenescence. Vaccine 2003;21:3826-3836.

32. Krabbe KS, Pedersen M, Bruunsgaard H. Inflammatory mediators in the elderly. Exp Gerontol 2004;39:687-699.

33. Schmaltz HN, Fried LP, Xue QL et al. Chronic cytomegalovirus infection and inflammation are associated with prevalent frailty in community-dwelling older women. J Am Geriatr Soc 2005;53:747-754.

34. Deatly AM, Haase AT, Fewster PH et al. Human herpes virus infections and Alzheimer's disease. Neuropathol Appl Neurobiol 1990;16:213-223.

35. Lin WR, Wozniak MA, Wilcock GK et al. Cytomegalovirus is present in a very high proportion of brains from vascular dementia patients. Neurobiol Dis 2002;9:82-87.

36. Lin WR, Wozniak MA, Cooper RJ et al. Herpesviruses in brain and Alzheimer's disease. J Pathol 2002;197:395-402.

37. Jamieson GA, Maitland NJ, Wilcock GK et al. Herpes simplex virus type 1 DNA is present in specific regions of brain from aged people with and without senile dementia of the Alzheimer type. J Pathol 1992;167:365-368.

38. Lin WR, Shang D, Wilcock GK et al. Alzheimer's disease, herpes simplex virus type 1, cold sores and apolipoprotein E4. Biochem Soc Trans 1995;23:594S.

39. Lin WR, Shang D, Itzhaki RF. Neurotropic viruses and Alzheimer disease. Interaction of herpes simplex type 1 virus and apolipoprotein $\mathrm{E}$ in the etiology of the disease. Mol Chem Neuropathol 1996;28:135-141.

40. Itzhaki RF, Lin WR, Shang D et al. Herpes simplex virus type 1 in brain and risk of Alzheimer's disease. Lancet 1997;349:241-244. 
41. Itabashi S, Arai H, Matsui Tet al. Herpes simplex virus and risk of Alzheimer's disease. Lancet 1997;349:1102.

42. Beffert U, Stolt PC, Herz J. Functions of lipoprotein receptors in neurons. J Lipid Res 2004;45:403-409.

43. Hemling N, Roytta M, Rinne J et al. Herpesviruses in brains in Alzheimer's and Parkinson's diseases. Ann Neurol 2003;54:267-271.

44. Itzhaki RF, Wozniak MA. Herpes simplex virus type 1 , apolipoprotein E, and cholesterol: A dangerous liaison in Alzheimer's disease and other disorders. Prog Lipid Res 2006;45:73-90.

45. Ravaglia G, Forti P, Maioli F et al. The clock-drawing test in elderly Italian community dwellers: Associations with sociodemographic status and risk factors for vascular cognitive impairment. Dement Geriatr Cogn Disord 2003;16: 287-295.

46. Teunissen CE, van Boxtel MP, Bosma $\mathrm{H}$ et al. Inflammation markers in relation to cognition in a healthy aging population. J Neuroimmunol 2003;134:142150 .

47. Engelhart MJ, Geerlings MI, Meijer J et al. Inflammatory proteins in plasma and the risk of dementia: The Rotterdam Study. Arch Neurol 2004;61:668672.

48. Duong T, Acton PJ, Johnson RA. The in vitro neuronal toxicity of pentraxins associated with Alzheimer's disease brain lesions. Brain Res 1998;813:303312 .

49. Duong T, Nikolaeva M, Acton PJ. C-reactive protein-like immunoreactivity in the neurofibrillary tangles of Alzheimer's disease. Brain Res 1997;749:152-156.

50. Iwamoto N, Nishiyama E, Ohwada J et al. Demonstration of CRP immunoreactivity in brains of Alzheimer's disease: Immunohistochemical study using formic acid pretreatment of tissue sections. Neurosci Lett 1994;177:23-26.

51. Lannergard A, Larsson A, Kragsbjerg P et al. Correlations between serum amyloid A protein and C-reactive protein in infectious diseases. Scand J Clin Lab Invest 2003;63:267-272.

52. Nakayama T, Sonoda S, Urano Tet al. Monitoring both serum amyloid protein $\mathrm{A}$ and C-reactive protein as inflammatory markers in infectious diseases. Clin Chem 1993;39:293-297.

53. Hyams KC, Cross ER, Bianco MA et al. Geographic risk factors for viral hepatitis and cytomegalovirus infection among United States Armed Forces blood donors. Transfusion 1992;32:644-647.

54. White NH, Yow MD, Demmler GJ et al. Prevalence of cytomegalovirus antibody in subjects between the ages of 6 and 22 years. J Infect Dis 1989;159:1013-1017.

55. Pulliam L, Moore D, West DC. Human cytomegalovirus induces IL-6 and TNF alpha from macrophages and microglial cells: Possible role in neurotoxicity. J Neurovirol 1995;1:219-227.

56. Perkins P, Annegers JF, Doody RS et al. Incidence and prevalence of dementia in a multiethnic cohort of municipal retirees. Neurology 1997;49:44-50.

57. Tang MX, Cross P, Andrews $\mathrm{H}$ et al. Incidence of AD in African-Americans, Caribbean Hispanics, and Caucasians in northern Manhattan. Neurology 2001;56:49-56.
58. Clark CM, DeCarli C, Mungas D et al. Earlier onset of Alzheimer disease symptoms in Latino individuals compared with Anglo individuals. Arch Neurol 2005;62:774-778.

59. Ringman JM, Flores DL. Earlier Alzheimer onset in Latino persons: Ethnic difference vs selection bias. Arch Neurol 2005;62:1786-1787.

60. Rivera VM. The terms Latino and Anglo and tendency to early Alzheimer disease. Arch Neurol 2005;62:1787, author reply 1787-1788.

61. Nahmias AJ, Lee FK, Beckman-Nahmias S. Sero-epidemiological and -sociological patterns of herpes simplex virus infection in the world. Scand J Infect Dis Suppl 1990;69:19-36.

62. Goade DE, Nofchissey RA, Kusewitt DF et al. Ultraviolet light induces reactivation in a murine model of cutaneous herpes simplex virus-1 infection. Photochem Photobiol 2001;74:108-114.

63. Glaser R, Kiecolt-Glaser JK. Chronic stress modulates the virus-specific immune response to latent herpes simplex virus type 1. Ann Behav Med 1997;19: 78-82.

64. Rawls W. Herpes simplex virus. In: Fields BN, ed. Virology. New York: Raven Press, 1985.

65. Biondi M, Zannino LG. Psychological stress, neuroimmunomodulation, and susceptibility to infectious diseases in animals and man: A review. Psychother Psychosom 1997;66:3-26.

66. Sainz B, Loutsch JM, Marquart ME et al. Stress-associated immunomodulation and herpes simplex virus infections. Med Hypotheses 2001;56:348-356.

67. Keller JN. Age-related neuropathology, cognitive decline, and Alzheimer's disease. Ageing Res Rev 2006;5:1-13.

68. Wilson RS, Bennett DA, Mendes de Leon CF et al. Distress proneness and cognitive decline in a population of older persons. Psychoneuroendocrinology 2005;30:11-17.

69. Leonard BE. Changes in the immune system in depression and dementia: Causal or co-incidental effects? Int J Dev Neurosci 2001;19:305-312.

70. Mitchell AJ. Depression as a risk factor for later dementia: A robust relationship? Age Ageing 2005;34:207-209.

71. Mehta SK, Stowe RP, Feiveson AH et al. Reactivation and shedding of cytomegalovirus in astronauts during spaceflight. J Infect Dis 2000;182:1761-1764.

72. Appels A, Bar FW, Bar J et al. Inflammation, depressive symptomtology, and coronary artery disease. Psychosom Med 2000;62:601-605.

73. Sarid O, Anson O, Yaari A et al. Human cytomegalovirus salivary antibodies as related to stress. Clin Lab 2002;48:297-305.

74. Ganguli MY, Dodge HH et al. Depressive symptoms and cognitive decline in late life: A prospective epidemiological study. Arch Gen Psychiatry 2006;63: 153-160.

75. Bassuk SS, Berkman LF, Wypij D. Depressive symptomatology and incident cognitive decline in an elderly community sample. Arch Gen Psychiatry 1998; 55:1073-1081.

76. Vercellotti GM. Overview of infections and cardiovascular diseases. J Allergy Clin Immunol 2001;108:S117-S120. 